\title{
Minimally Invasive Image Guided Interventions in Gynaecology and Women's Health
}

\author{
Dr Arindam Bharadwaz ${ }^{1,2 *}$ \\ ${ }^{1}$ Senior Consultant, Department of Radiology, Aarhus University Hospital, Denmark \\ ${ }^{2}$ President, Danish Society of Interventional Radiology, Denmark
}

Received: 䟧 April 05, 2018; Published: 制 April 12, 2018

*Corresponding author: Dr Arindam Bharadwaz, Senior Consultant, Department of Radiology, Aarhus University Hospital, Denmark, Email: arinbhar@rm.dk

Abbreviations: RCOG: Royal College of Obstetrics \& Gynaecologists; UAE: Uterine Artery Embolisation; CPP: Chronic Pelvic Pain; PCS: Pelvic Congestion Syndrome

\section{Introduction}

Image guided interventions are increasingly being used in different fields of medicine. A large number of such minimally invasive interventions are routinely done for surgical, medical and oncological patients, besides the endovascular interventions performed for a variety of vascular conditions and diseases. Minimally invasive image guided interventions in gynaecology are primarily embolisation procedures where supplying arteries or draining veins are occluded using different embolisation materials. The major image guided interventions are described below.

\section{Haemorrhage}

Uterine and pelvic arterial embolisation is a life saving tool for post partum haemorrhage $(\mathrm{PPH})[1,2]$, post-operative bleeding including after caesarian section and hysterectomy, and for bleeding (or risk of bleeding) in abnormal placentation, post-abortion/ectopic pregnancy, trophoblastic disorders and gynaecological malignancies [3]. The embolisation techniques are minimally invasive, quick and easy to Perform, saves a lot of blood transfusion and patients recover early with shorter hospital stay. Most embolisations are performed through a puncture in the right and/or left common femoral artery and use 4F-5F selective catheters, co-axial micro catheters $(2.4 \mathrm{~F}-3 \mathrm{~F})$ and corresponding guide wires. Typical embolisation materials used to occlude the bleeding vessels are coils (steel, platinum, fibred or hydro gel coils), particles (uncalibrated gel foam, calibrated particles from 500-900 micron) and liquid embolic materials (Glue \& Onyx). Coils and Gel foam are the most frequently used embolic agents (Figures 1-3).
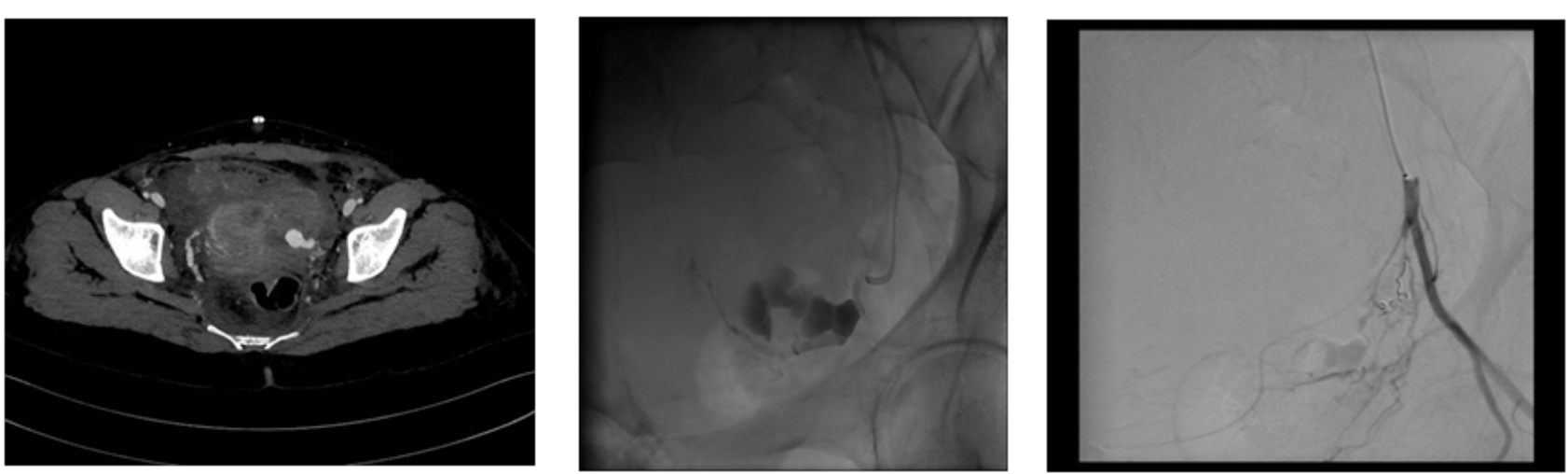

Figure 1,2,3: CT scanning reveals pseudo aneurysm and active bleeding from left uterine artery after caesarian section. Patient continued to lose significant blood despite packing and re-look surgery. Hb fell significantly and patient was moribund. Angiography reveals a large active bleeding from left uterine artery embolised successfully with a micro coil. Patient had an uneventful recovery after embolisation. 


\section{Uterine Fibroids}

Leiomyomas occur in $50-60 \%$ of women, rising to $70 \%$ by the age of 50 [4]. It causes pressure symptoms such urinary symptoms, heaviness, pelvic pain, infertility and obstetric complications, and in $30 \%$ of cases, cause heavy menstrual bleeding leading to anemia [5]. Effectiveness of uterine artery embolisation (UAE) in treating selected patients with uterine fibroids has been established by multiple studies. Royal College of Obstetrics \& Gynaecologists (RCOG) recommends that UAE should always be considered along with surgical options [6]. UAE has similar outcome as surgery in up to a five-year follow up with no greater major complication rate
[7]. On the other hand UAE is minimally invasive, can be performed on a day-care basis and thus has very short hospital stay compared to surgery, though with a higher re-intervention rate in the long term. Pre-treatment and follow up MR scanning is mandatory to diagnose, plan intervention and evaluate treatment success and rule out complications. UAE is always performed bilaterally as leiomyomas tend to have bilateral uterine arterial supply. 500-900 micron particles are used for embolisation until complete stasis of the uterine arteries. Smaller particles are usually not recommended to avoid complications such as necrosis of fibroid/ uterus. Cervical branches should also be avoided during UAE (Figures 4-9).
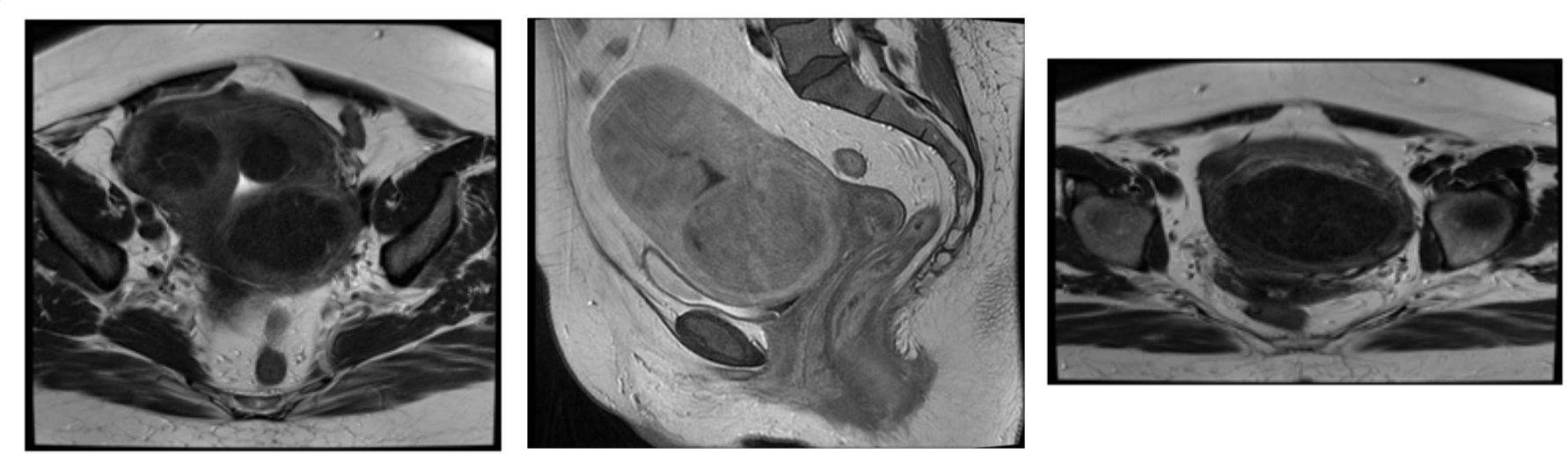

Figure 4,5 \& 6: MR images show multiple large fibroids in uterus.

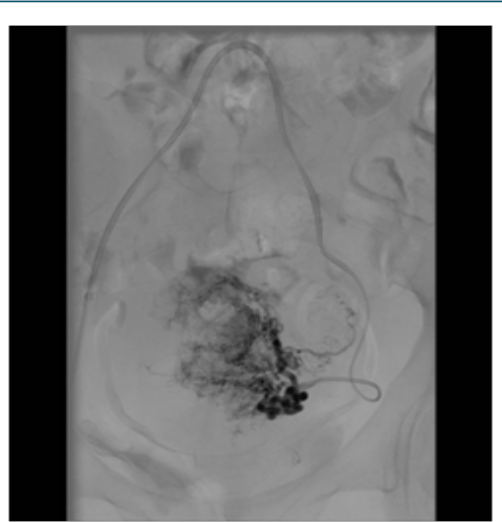

Figure 7: Bilateral uterine artery embolisation (UAE).

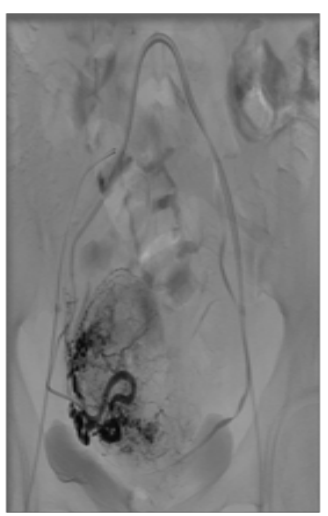

Figure 8: Bilateral uterine artery embolisation (UAE).

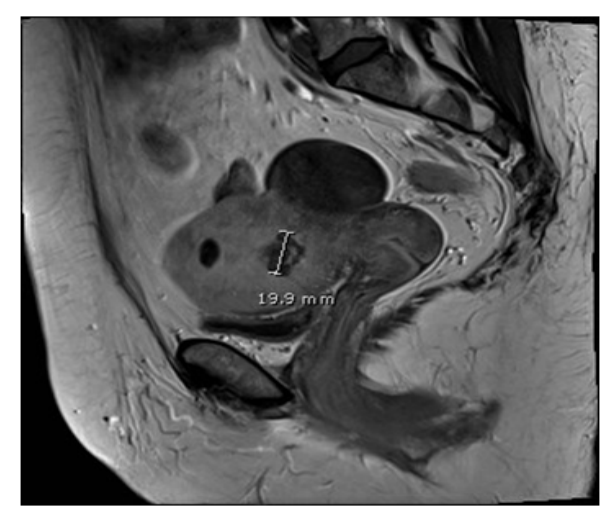

Figure 9: Significant shrinkage of fibroids after UAE.

\section{Pelvic Congestion Syndrome (PCS)}

PCS is a differential diagnosis for a patient with chronic pelvic pain (CPP), which is present in about $2-24 \%$ women from $18-50$ years of age [8]. The prevalence of PCS in patients with PCC is about $10-30 \%$, where no other obvious pathologies have been found [9]. Symptoms of PCS include CPP lasting at least 3-6 months, heaviness, pain during and after coitus, pain that can be exacerbated before or during menses, relived in supine position and can last several hours at a time. Diagnostic modalities are transvaginal color Doppler scanning, MR and contrast CT scanning. Although medical and surgical treatments are available for the treatment of PCS, pelvic venous embolisation is currently considered the best treatment available for the treatment of PCS [10]. Ovarian and pelvic vein 
embolisation has been recommended as the standard of care with grade 2B recommendation by Society for vascular Surgery and American Venous Forum [11]. Refluxing ovarian and iliac veins can be approached from femoral, jugular, subclavian and brachial routes, all with high technical success and low complication rates [12]. Various embolic materials have been used in embolisation for PCS including coils, foam (sclerotherapy), glue, plugs etc. However coil-embolisation and/or foam sclerotherapy are most commonly used techniques. Clinical success rate has been described from about $70-100 \%$ in various studies although there lacks a well designed larged randomised control trial [10]. Complication rate is low and minor, a majority (around 15\%) of which is self limiting post-embolisation syndrome [13-15] (Figures 10-12).
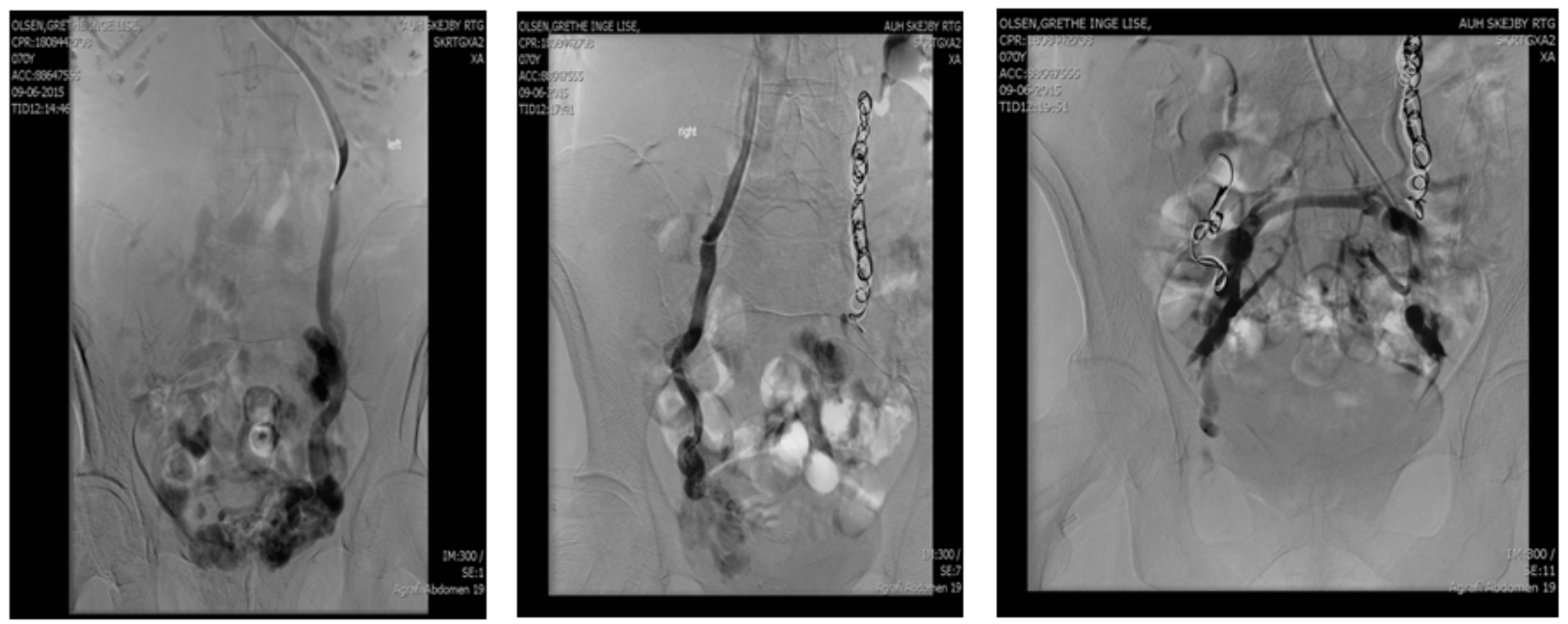

Figure 10,11,12: A woman with PCS during phlebography shows large incompetent bilateral ovarian veins, particularly on the left side crossing the midline and communicating with each other. Successful embolisation of both ovarian veins with macrocoils.

\section{Conclusion}

The role of minimally invasive image guided interventions in gynaecology is constantly evolving and is best defined in a multidisciplinary setting where decisions for interventions are jointly taken by the gynaecologist and the interventional radiologist. Many of the procedures can be performed under local anaesthesia or conscious sedation, in a day care basis in a minimally invasive manner with short hospital stay and very low complication rate. Most complications are minor and are either self limiting or require minimal medication/therapy. The role of image guided intervention in gynecology and women's health can be life saving, assisting in surgery by decreasing vascularily and blood loss in the operating field or significantly improve symptoms and quality of life.

\section{References}

1. Pelage JP, Le Dref O, Mateo J, Soyer P, Jacob D, et al. (1998) Lifethreatening primary postpartum hemorrhage: treatment with selective arterial embolization. Radiology 208(2): 359-362.

2. (2007) Royal College of Obstetricians and Gynaecologists. The role of emergency and elective interventional radiology in postpartum hemorrhage. Royal College of Obstetricians and Gynaecologists Good Practice Guideline No. 6. Royal College of Obstetricians and Gynaecologists, London.

3. Malik SN, Shams M (2012) Role of Uterine Artery Embolization in the Management of Cervical Cancer: Review Article J Cancer Sci Ther 4(6): 167-169.
4. Baird D, Dunson DB, Hill MC, Cousins D, Schectman JM (2003) High cumulative incidence of uterine leiomyoma in black and white women: ultrasound evidence. Am J Obstet Gynecol 188(1): 100-107.

5. Donnez J, Jadoul P (2002) What are the implications of myomas on fertility? A need for a debate? Hum Reprod 17(6): 1424-1430.

6. (2013) Clinical recommendations on the use of uterine artery embolisation (UAE) in the management of fibroids. Royal college of Obstetricians \& Gynaecologists ( $\left.3^{\text {rd }} \mathrm{edn}\right)$.

7. Gupta JK, Sinha AS, Lumsden MA, Hickey M (2006) Uterine artery embolization for symptomatic uterine fibroids. Cochrane Database Syst Rev 16(5): CD005073.

8. Latthe P, Latthe M, Say L, Gülmezoglu M, Khan KS (2006) WHO systematic review of prevalence of chronic pelvic pain: a neglected reproductive health morbidity. BMC Public Health 6: 177.

9. Fassiadis N (2006) Treatment for pelvic congestion syndrome causing pelvic and vulvar varices. Int Angiol 25(1): 1-3.

10. Borghi C, Dell'Atti L (2016) Pelvic congestion syndrome: the current state of the literature. Arch Gynecol Obstet 293(2): 291-301.

11. Gloviczki P, Comerota AJ, Dalsing MC, Eklof BG, Gillespie DL, et al. (2011) The care of patients with varicose veins and associated chronic venous diseases: clinical practice guidelines of the Society for Vascular Surgery and the American Venous Forum. J Vasc Surg 53(5 Suppl): 2S-48S.

12. Freedman J, Ganeshan A, Crowe PM (2010) Pelvic congestion syndrome: the role of interventional radiology in the treatment of chronic pelvic pain. Postgrad Med J 86(1022): 704-710.

13. Hansrani V, Abbas A, Bhandari S, Caress AL, Seif M, et al. (2015) Transvenous occlusion of incompetent pelvic veins for chronic pelvic pain in 
women: a systematic review. Eur J Obstet Gynecol Reprod Biol 185: 156163.

14. Van der Vleuten CJ, van Kempen JA, Schultze Kool LJ (2012) Embolization to treat pelvic congestion syndrome and vulval varicose veins. Int J Gynaecol Obstet. 118(3): 227-230.
15. Laborda A, Medrano J, de Blas I, Urtiaga I, Carnevale FC, et al. (2013) Endovascular treatment of pelvic congestion syndrome: visual analog scale (VAS) long-term follow-up clinical evaluation in 202 patients. Cardiovasc Intervent Radiol 36(4): 1006-1014.

\section{(c) (?) \\ This work is licensed under Creative \\ Commons Attribution 4.0 License}

To Submit Your Article Click Here: Submit Article

DOI: 10.32474/IGWHC.2018.01.000121

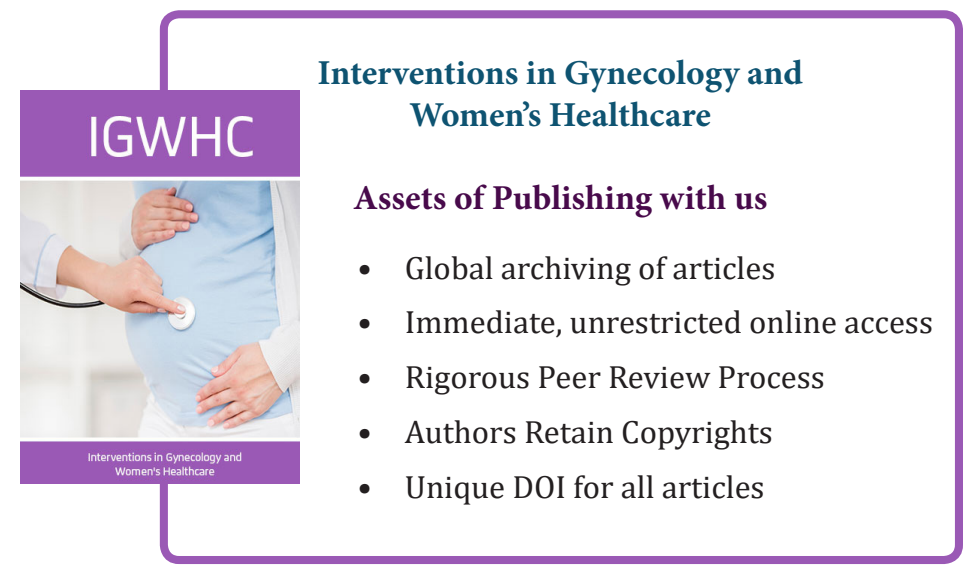

